\title{
Intramural Hematoma of the Esophagus
}

\author{
Dahlia Thao Cao ${ }^{a} \quad J e a n-L u c$ Reny ${ }^{b} \quad$ Nicolas Lanthier $^{a}$ \\ Jean-Louis Frossard ${ }^{a}$ \\ ${ }^{a}$ Department of Medical Specialties, Gastroenterology and Hepatology Division, \\ and ${ }^{\mathrm{b}}$ Department of Internal Medicine, Rehabilitation and Geriatrics, General \\ Internal Medicine Division, University Hospitals and Faculty of Medicine of \\ Geneva, Geneva, Switzerland
}

\section{Key Words}

Intramural $\cdot$ Hematoma $\cdot$ Esophagus

\begin{abstract}
We report the case of a patient with an intramural hematoma of the esophagus. This rare condition is more common in elderly women and can be misdiagnosed as cardiovascular or other digestive emergent disease. The classical clinical triad includes chest pain, sudden dysphagia or odynophagia and minor hematemesis. Known precipitating factors are Valsalva maneuver, blunt, direct or iatrogenic injuries, but spontaneous cases have also been described. Chest imaging including computed tomography or magnetic resonance imaging as well as upper gastrointestinal endoscopy are useful tools for diagnosis. The treatment is conservative and the prognosis usually excellent with complete resolution within a few weeks.
\end{abstract}

\section{Introduction}

Intramural hematoma of the esophagus is a rare condition; it is more common in elderly women and can be misdiagnosed as cardiovascular or other digestive emergent disease. The classical clinical triad includes chest pain, sudden dysphagia or odynophagia and minor hematemesis. Known precipitating factors are Valsalva maneuver, blunt, direct or iatrogenic injuries, but spontaneous cases have also been described. Chest imaging including computed tomography (CT) or magnetic resonance imaging (MRI) as well as upper gastrointestinal endoscopy are useful tools for diagnosis. The treatment is conservative and the prognosis usually excellent with complete resolution within a few weeks. 


\section{Case Report}

An 83-year-old Caucasian woman with hyperlipemia and previous low back pain was admitted to the hospital because of a sudden onset of sharp interscapular pain after a bout of cough. The patient had been treated for viral bronchitis one week before admission. She reported no dysphagia, odynophagia, hematemesis, fever or weight loss. Her home medication included Mefenacid and simvastatin. Upon admission, vital signs were normal (blood pressure 120/70 $\mathrm{mm} \mathrm{Hg}$, heart rate $86 /$ min, temperature $36.3^{\circ} \mathrm{C}$, oxygen saturation $97 \%$ ). Physical examination was unremarkable. Normal electrocardiogram and normal cardiac enzymes ruled out a myocardial infarction. Laboratory tests, including liver enzymes, platelet count and hemostasis, were within normal range, and chest $\mathrm{X}$-ray was normal. A thoracic CT scan ruled out a dissection of the aorta, but revealed an obstructive esophageal mass located in the median and lower part of the esophagus (fig. 1, fig. 2 ). We performed an upper gastrointestinal endoscopy which showed a large obstructive blue lesion in the esophagus extending from 22 to $36 \mathrm{~cm}$ distal from the incisors, suggesting a large intramural hematoma of the esophagus (fig. 3 , fig. 4). MRI confirmed the esophageal mass of intermediate signal intensity on T1and T2-weighted image (fig. 5). The patient was managed conservatively with no food or drink intake for $24 \mathrm{~h}$, then allowed a soft diet as she could tolerate, and discharged after 10 days. Repeat endoscopy 14 days later showed that the lesion was healing.

\section{Discussion}

Intramural hematoma of the esophagus or dissecting intramural hematoma of the esophagus or intramural rupture of the esophagus or esophageal apoplexy is a rare condition characterized by a collection of blood in the wall of the esophagus $[1,2]$. A review of 174 reported cases shows that patients are middle-aged (average of 58.8 years) with a bimodal distribution with a first peak at 45 years and a second peak of greater magnitude around 70 years. The condition is slightly more frequent in females [1]. Our case was typical for both of these latter characteristics.

The classical clinical presentation includes chest pain (84\%) associated with dysphagia or odynophagia (59\%), followed by minor hematemesis (56\%). Ninety percent of patients have at least one of these symptoms, $79 \%$ two or more and one third all symptoms [1]. The chest pain is usually of sudden onset, severe, retrosternal or epigastric with occasional radiating to the back, as was the case for our patient [2]. The pain is explained by sudden and massive distention in the esophageal wall. The hematemesis occurs after dissection of the hematoma through the esophageal mucosa [3]. Clinical examination is usually unremarkable, but in a few cases low blood pressure, tender epigastrium or low-grade fever may be present [1].

The causes can be divided into five categories: related to abnormal hemostasis, emetogenic, traumatic/iatrogenic, related to aortic disease or spontaneous [4]. Coagulation disorders, anticoagulant or antiplatelet agents are not causative but rather aggravating factors $[2,5]$. Antiplatelet drugs are postulated to extend the hematoma rather than causing submucosal bleeding [6]. In hemostasis disorders, a primary submucosal bleed followed by a possible secondary rupture in the esophageal lumen often occurs without vomiting [3].

Valsalva maneuver is involved in about one third of cases. Vomiting, coughing, sneezing, swallowing hurriedly a too compact or bulky bolus, or lifting a heavy weight may be precipitating factors [7]. The postulated mechanism is a sudden change in intrathoracic and esophageal pressure during uncoordinated movements while swallowing or vomiting [1]. It results in a transverse tear in the mucosa membrane 
which dissects downwards from the mucosa layer [8] through the esophageal submucosa [3]. In our case, a bout of cough was probably the precipitating factor and the intramural hematoma was located in the middle and lower part of the esophagus. The site of injury is commonly the distal esophagus (83\%). The reason is a lack of striated muscle and support by adjacent structures like trachea and heart and by the fiber of the muscularis splaying out towards the gastroesophageal junction to form the muscular coat of the stomach [1]. The middle part of the esophagus is involved in $78 \%$ and the proximal portion in $27 \%$ [1]. The mucosal tears are transverse and submucosal hematoma can secondarily rupture in the esophageal lumen $[1,5]$. Intramural hematoma of the esophagus can occur with or without a discrete mucosal tear [3]. The intramural hematoma may be concentric or eccentric, depending on its extension [4].

Direct injuries are caused by endoscopic interventions, ingested matter or external injury of the chest wall [1]. Case reports describe intramural hematoma of the esophagus after varix sclerotherapy, esophageal dilatation, pill impaction or road traffic accidents [1]. Aortoesophageal fistula is a rare life-threatening cause of intramural hematoma of the esophagus. It may be secondary to aortic (75\%) or esophageal conditions. Aortic pathologies include ruptured atheromatous aneurysm, complication of prosthetic aortic grafting and aortic surgery. Esophageal secondary causes are foreign body ingestion, esophageal malignancies or corrosive esophagitis or penetrating ulcer [4]. In 19\% of cases, no precipitating factor is described. Esophageal motility troubles can precipitate an intramural hematoma [1].

The clinical differential diagnosis of intramural hematoma of the esophagus includes esophageal lesions like Boerhaave or Mallory-Weiss syndrome [5]. Boerhaave syndrome is a complete transmural rupture of the distal esophagus by sudden increase of intraesophageal pressure following violent vomiting, severe cough, blunt trauma, child birth, straining and weight lifting. The classical clinical presentation is Mackler's triad: vomiting, lower thoracic pain and subcutaneous emphysema. The tear and rupture occur in the lower third of the esophagus [3]. Boerhaave syndrome has a high mortality rate and usually requires emergent surgery [6]. Mallory-Weiss syndrome is a longitudinal mucosal tear at the gastroesophageal junction or gastric cardia following severe cough, retching or forceful vomiting. The usual symptom is hematemesis [6]. The prognosis is excellent with conservative treatment [6]. Intramural hematoma of the esophagus can also be misdiagnosed as other digestive pathologies such as perforated peptic ulcer and pancreatitis [6], cardiac or vascular diseases such as ischemic heart disease, dissection or aneurysm rupture of the thoracic aorta [3] or pulmonary embolism [9], or pulmonary lesions such as pneumothorax [10].

Additional tests such as electrocardiogram, chest X-ray and laboratory tests are useful to rule out cardiovascular and respiratory conditions [7]. Investigations to identify an intramural hematoma of the esophagus were historically barium or Gastrografin swallow. Nowadays, chest CT or MRI, upper gastrointestinal endoscopy [1] and endoscopic ultrasonography are often performed [11]. Barium or Gastrografin swallow was historically the main radiological imaging [12] showing an elongated tubular filling defect with smooth margins or with a stripe of contrast filling the dissection space as well as the lumen of the esophagus (mucosal stripe sign or double-barreled esophagus) [1]. Currently, chest CT is the initial rapid and noninvasive radiological investigation of choice and can rule out other thoracic pathologies. CT 
usually shows symmetric or asymmetric esophageal wall thickening and a well-defined nonenhancing, high-attenuation intramural esophageal mass extending along the esophageal wall [4]. The characteristic feature of MRI is a mass of intermediate signal intensity on T1- and T2-weighted image. MRI shows the extension of the hematoma in various planes and be useful to differentiate esophageal lesions from other mediastinal pathologies [6]. Upper gastrointestinal endoscopy usually shows a large, fluctuant blue or purplish lesion descending down the posterior esophagus [1] or sometimes mucosal erosions, ulcerations or necrosis in the case of extensive submucosal lesion [11]. The endoscopic lesion can be confounded with a large varix or a tumor of the esophagus [5]. Endoscopic ultrasonography may be helpful to further identify underlying esophageal tumors or vascular lesions typically seen as homogeneously hypoechoic lesions within the submucosal layer [4] and no Doppler vascular signal in the submucosa [11]. In our case, we performed a chest CT and MRI and upper gastrointestinal endoscopy that showed the same lesions as the previously described cases.

Treatment is conservative with no oral food or drink intake, intravenous fluid, then a progressive reintroduction of fluid and soft diet and correction of any coagulopathy [2]. Except for rare cases of infection trapped in the submucosal layer, there is no indication for antibiotics [1]. Surgery is contraindicated except for esophageal perforation, ongoing hemorrhage or undrained complicated abscess. In case of no spontaneous resolution of the intramural hematoma of the esophagus, endoscopic incision of the mucosal bridge has been described [12].

The prognosis is excellent with healing in about 2 weeks leading to full recovery $(75 \%)$ like in our case. Death has been reported after thoracotomy or in terminally ill patients [1]. Recurrent massive bleeding was described as a complication of intramural hematoma of the esophagus and managed with arterial embolization [13]. Recurrence is reported with achalasia [1]. The lesion can be followed by endoscopy [5] or echoendoscopy [14].

\section{Conclusion}

The review is based on observational studies, case series and individual reports on intramural hematoma of the esophagus. There are publication biases, probably underreporting new cases because of the rarity of this condition. The recommendations are considered as weak [15], but we recommend definitely ruling out any insidious underlying cancer.

\section{Acknowledgement}

The authors acknowledge the help of Sylvain Terraz, Department of Radiology, University Hospitals and Faculty of Medicine of Geneva, Switzerland.

\section{Disclosure Statement}

The authors declare that they have no competing interest. 


\begin{tabular}{r|l|l|l}
$\begin{array}{r}\text { Case Reports in } \\
\text { Gastroenterology }\end{array}$ & $\begin{array}{l}\text { Case Rep Gastroenterol 2012;6:510-517 } \\
\text { DOI: 10.1159/000341808 }\end{array}$ & $\begin{array}{l}\text { Published online: } \\
\text { July 26, 2012 }\end{array}$ & $\begin{array}{l}\text { @ 2012 S. Karger AG, Basel } \\
\text { ISSN 1662-0631 } \\
\text { www.karger.com/crg }\end{array}$ \\
\hline
\end{tabular}

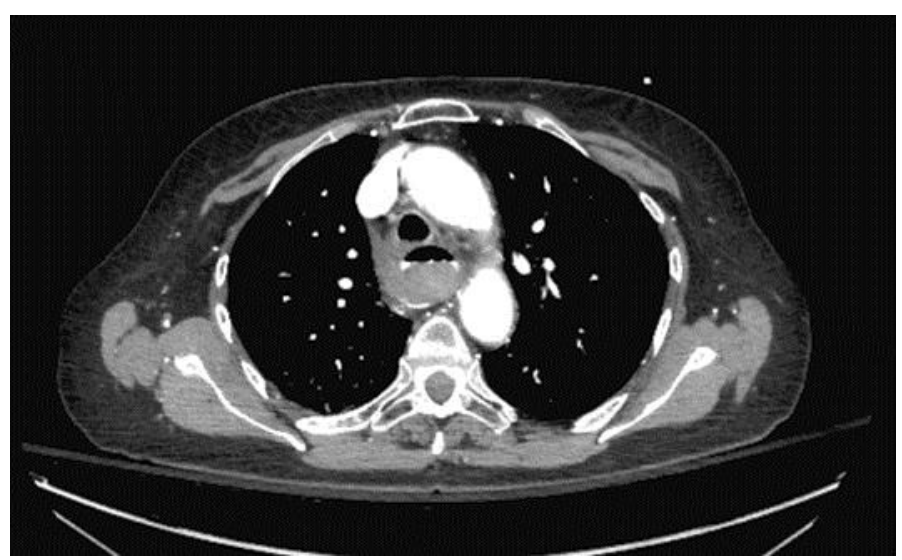

Fig. 1. Chest CT: obstructive esophageal mass located in the median and lower part of the esophagus.

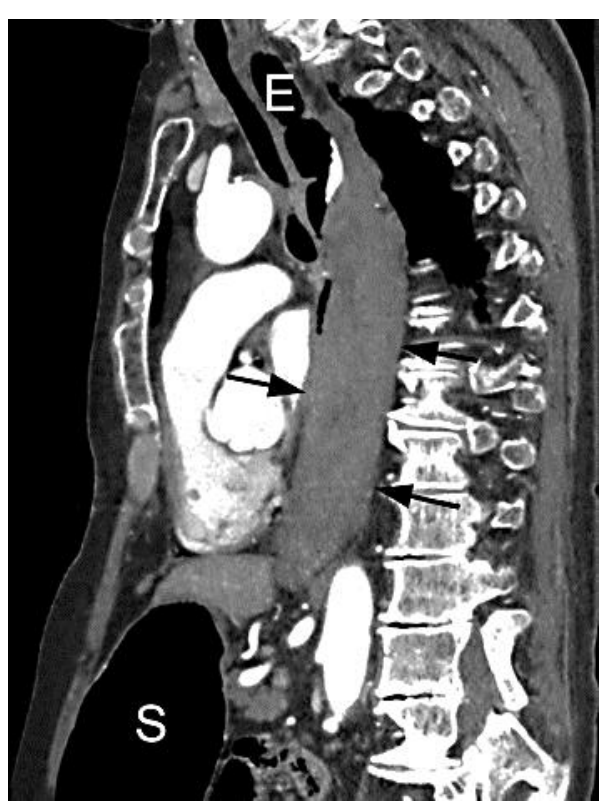

Fig. 2. Chest CT: obstructive esophageal mass located in the median and lower part of the esophagus in sagittal reconstruction. $\mathrm{E}=$ Esophagus; $\mathrm{S}$ = stomach. 


\begin{tabular}{r|l|l|l}
$\begin{array}{r}\text { Case Reports in } \\
\text { Gastroenterology }\end{array}$ & $\begin{array}{l}\text { Case Rep Gastroenterol 2012;6:510-517 } \\
\text { DOI: 10.1159/000341808 }\end{array}$ & $\begin{array}{l}\text { Published online: } \\
\text { July 26, 2012 }\end{array}$ & $\begin{array}{l}\text { @ 2012 S. Karger AG, Basel } \\
\text { ISSN 1662-0631 } \\
\text { www.karger.com/crg }\end{array}$ \\
\hline
\end{tabular}

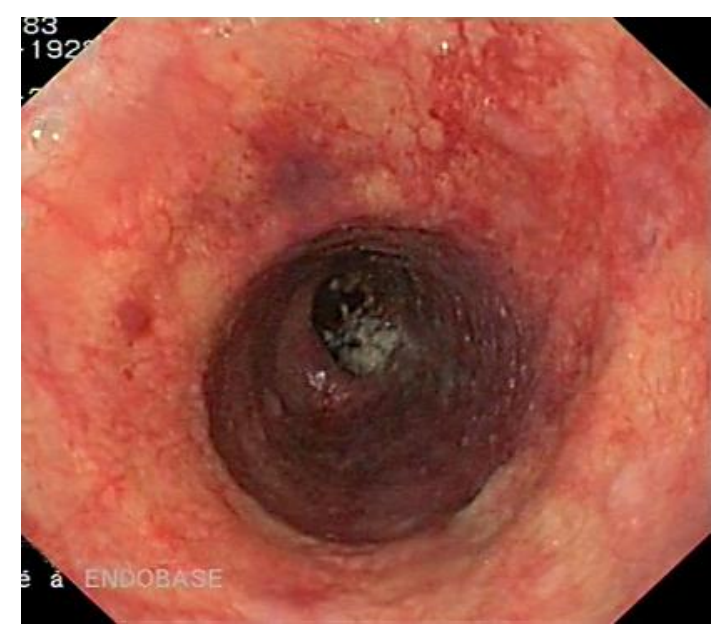

Fig. 3. Upper gastrointestinal endoscopy: large obstructive blue lesion in the esophagus extending from 22 to $36 \mathrm{~cm}$ distal from the incisors.

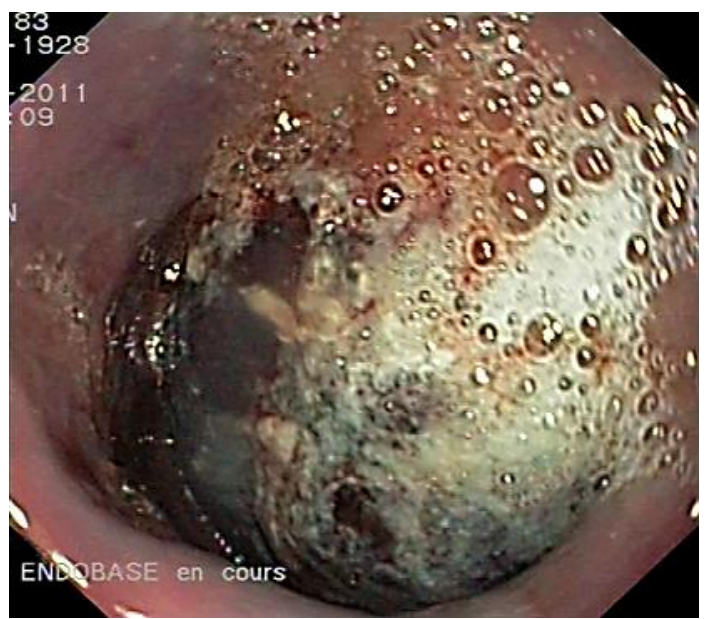

Fig. 4. Upper gastrointestinal endoscopy: large obstructive blue lesion in the esophagus. 


\begin{tabular}{r|l|l|l}
$\begin{array}{r}\text { Case Reports in } \\
\text { Gastroenterology }\end{array}$ & $\begin{array}{l}\text { Case Rep Gastroenterol 2012;6:510-517 } \\
\text { DOI: 10.1159/000341808 }\end{array}$ & $\begin{array}{l}\text { Published online: } \\
\text { July 26, 2012 }\end{array}$ & $\begin{array}{l}\text { @ 2012 S. Karger AG, Basel } \\
\text { ISSN 1662-0631 } \\
\text { www.karger.com/crg }\end{array}$ \\
\hline
\end{tabular}

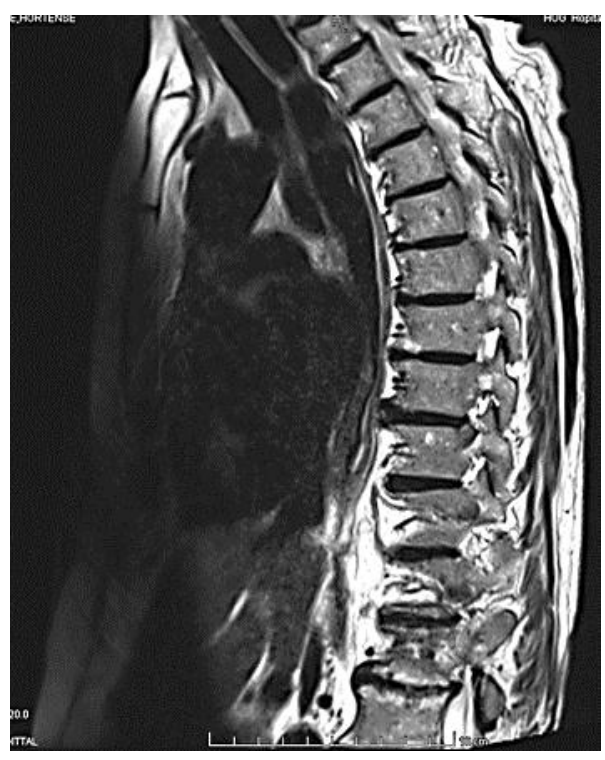

Fig. 5. MRI: partially obstructive esophageal mass located in the median and lower part of the esophagus in sagittal reconstruction.

\section{References}

1 Cullen SN, McIntyre AS: Dissecting intramural haematoma of the esophagus. Eur J Gastroenterol Hepatol 2000;12:1151-1162.

2 Meulman N, Evans J, Watson A: Spontaneous intramural haematoma of the oesophagus; a report of three cases and review of the literature. Aust N Z J Surg 1994;64:190-193.

-3 Ackert JJ, Sherman A, Lustbader IJ, McCauley DI: Spontaneous intramural hematoma of the esophagus. Am J Gastroenterol 1989;84:1325-1328.

-4 Katabathina V, Restrepo CS, Martinez-Jimenez S, Riascos RF: Nonvascular, nontraumatic mediastinal emergencies in adults: a comprehensive review of imaging findings. Radiographics 2011;31:1141-1160.

5 Van Laethem JL, Devière J, Cremer M: Serial endoscopic findings of spontaneous intramural hematoma of the esophagus. Endoscopy 1997;29:44-46.

6 Hiller N, Zagal I, Haldas-Halpern I: Spontaneous intramural hematoma of the esophagus. Am J Gastroenterol 1999;94:2282-2284.

7 Sabbah P, Debonne JM, Tomasini P, Barthet M, Guillot D, Salamand P, Klotz F, Briant JF: Hématome spontané intramural de l'oesophage. J Radiol 1994;75:121-124.

-8 Kuo YC, Wu CS: Spontaneous intramural perforation of the esophagus: case report and review of the literature. Endoscopy 1989;21:153-154.

-9 Strowd RE, Agborbesong P, Eapen M, Ervin S: Intramural hematoma of the esophagus presenting as chest pain. J Hosp Med 2010;5:421-423.

10 Clark W, Cook IJ: Spontaneous intramural haematoma of the oesophagus: radiologic recognition. Australas Radiol 1996;40:269-272.

11 Ho CL, Young TH, Yu CY, Chao YC: Intramural hematoma of the esophagus: ED diagnosis and treatment. Am J Emerg Med 1997;15:322-323.

$\$ 12$ Hsu CC, Changchien CS: Endoscopic and radiological features of intramural esophageal dissection. Endoscopy 2001;33:379-381. 
13 Shim J, Jang Y, Hwangbo Y, Dong SH, Oh JH, Kim BH, Chang YW, Chang R: Recurrent massive bleeding due to dissecting intramural hematoma of the esophagus: treatment with therapeutic angiography. World J Gastroenterol 2009;15:5232-5235.

14 Mion F, Bernard G, Valette PJ, Lambert R: Spontaneous esophageal hematoma: diagnostic contribution of echoendoscopy. Gastrointest Endosc 1994;40:503-505.

15 Hagel J, Bicknell SG, Haniak W: Imaging management of spontaneous giant esophageal intramural hematoma. Can J Assoc Radiol 2007;58:76-78. 